\title{
Socio-demographic and Subjective Factors Related to a Psychosocial and Biomedical Model of Successful Ageing
}

\author{
(1) Cem Soylu, (1) Türkan Yılmaz Irmak \\ Ege University Faculty of Arts, Department of Psychology, Izmir, Turkey
}

\begin{abstract}
Objective: With the number and proportion of older adults increasing worldwide, successful ageing (SA) has become a global goal. This study aimed to examine the association of subjective age, health and socio-demographic factors with the biomedical and psychosocial dimensions of SA.

Materials and Methods: A total of 61 adults, aged $\geq 50$ (mean age 67.1 \pm 9.4 ) years, living in nursing homes or in the community, were asked to answer a series of questions. A biomedical model of SA was measured by Rowe and Kahn's criteria (i.e. being free of disease and disability, having high physical and cognitive functioning and being actively engaged in life). A psychological well-being scale was used as an indicator of successful psychosocial ageing.
\end{abstract}

Results: Our analysis revealed that being married and younger by chronological age, having a high educational level, having a younger subjective age and having better subjective health are correlated with both the biomedical and psychosocial dimensions of SA. Neither gender nor the number of children was correlated with these dimensions.

Conclusion: The biomedical and psychosocial dimensions of SA are associated with similar socio-demographic factors along with subjective health and age. These findings suggest that subjective age and health status, which are changeable and relatively under the control of the individuals, are important to promote SA. Future research in this field can measure SA by creating an index that includes components of Rowe and Kahn's model and psychosocial indicators of SA.

Keywords: Healthy ageing, Rowe and Kahn's model, successful ageing

\section{Introduction}

Successful aging $(\mathrm{SA})$ is worldwide and an important concept that is widely discussed in gerontology today (1). As the number and the proportion of older adults continue to grow around the world as well as in Turkey (2), this concept draw great interest both to individuals and societies.

Over the past few decades, SA has been studied from different vantage points which reflected psychosocial or biomedical approaches or combinations of the two (3). One of the most influential conceptualisations of SA in a biomedical model was put forth by McLaughlin et al. (4) in the late 1980s, and this model has played a major role in the literature. In the year 1997, Rowe and Kahn (5) more explicitly defined the three main components of SA, including: (a) the absence of chronic disease and disability; (b) high physical and cognitive functioning; and (c) active engagement with life. To be a successful adult, an individual had to meet all three criteria. While the biomedical model emphasises the maintenance of mental and physical functioning as the keys to aging successfully, psychosocial models emphasize psychological resources, well-being and life satisfaction, including contentment and happiness (3).

There are an increasing number of studies on the factors that influence $S A$, and most of them have examined only the biomedical dimension (i.e., Rowe and Kahn's components, either singularly or in various combinations) or the psychosocial dimension (i.e., well-being and life satisfaction) of SA (6). However, there are very few studies which examined factors related to SA in terms of both the biomedical and psychosocial approaches. In addition, longitudinal and cross-sectional studies

Address for Correspondence: Cem Soylu, Ege University Faculty of Arts, Department of Psychology, İzmir, Turkey

Phone: +90 2323111331 E-mail: csoylu@hacettepe.edu.tr ORCID: orcid.org/0000-0002-6250-3450

Received: 01.10.2020 Accepted: 27.01.2021

Cite this article as: Soylu C, Yılmaz Irmak T. Socio-demographic and Subjective Factors Related to a Psychosocial and Biomedical Model of Successful Ageing.

Eur J Geriatr Gerontol 2021;3(2):124-130

๑Copyright 2021 by the Academic Geriatrics Society / European Journal of Geriatrics and Gerontology published by Galenos Publishing House. 
conducted in line with this purpose have mainly focused on socio-demographic factors (e.g., educational level, age, and marital status). There is very little known about the relationship between subjective health, age, and the dimensions of SA. For that reason, the purpose of the current study was to examine how current socio-demographic variables, subjective age and health are related to both the biomedical and the psychosocial models of SA. In that respect, our findings are inclusive of

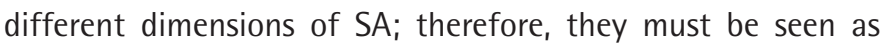
exploratory.

\section{Materials and Methods}

The study included adults who lived in private nursing homes or who lived in the larger community in Turkey between April and June of 2019. Adults were considered eligible for participation if they: a) were aged 50 or older; and b) scored more than 19 points on the "standardized mini mental state examination test (SMMSE)".

A total of 68 participants were identified who were eligible for participation. Four adults didn't complete some of the items and were thus excluded from the analyses. Three participants were regarded as outliers on one or more variables and were therefore excluded. As a result, all analyses were performed on the data from 61 participants. The baseline characteristics of the participants are showned in Table 1.

The study was approved by the Ethics Board and Commission of Ege University in Turkey (approval number=204-2019). All participants provided written and verbally informed consent.

\section{Subjective age and health}

Similar to Stephan et al. (7) study, participants were asked to specify, in years, how old they felt most of the time. A subjective age score was computed by subtracting one's perceived age from one's chronological age. Higher scores reflected a younger age identity. In line with previous studies $(8,9)$, subjective health was assessed using one item: "How would you describe your current health?". Participants rated their current health status on a five-point rating scale, from 1 (very bad) to 5 (very good).

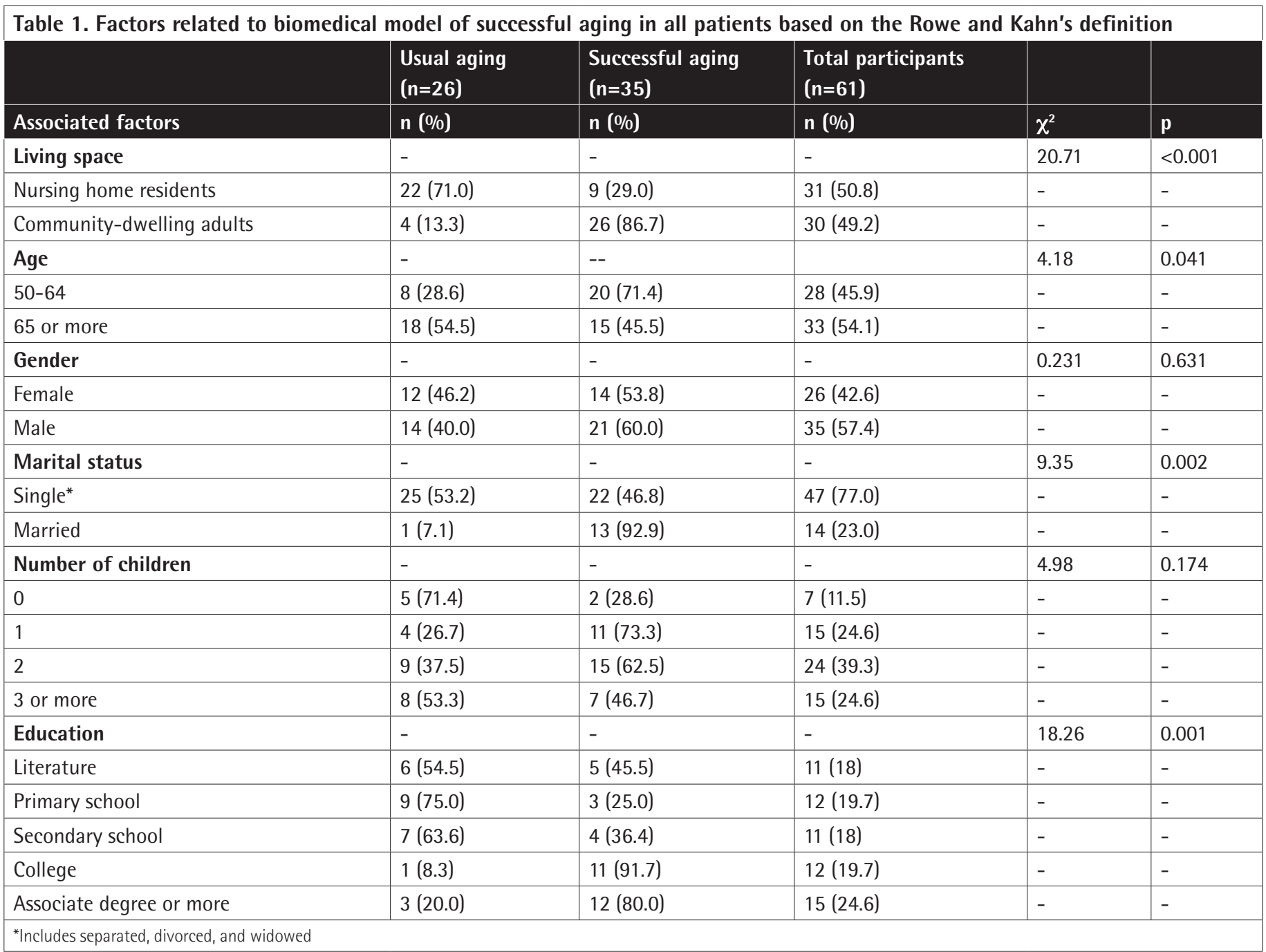




\section{Chronic diseases and disability}

To assess the number of chronic health conditions, participants were asked whether they had any chronic diseases (e.g., cholesterol or osteoporosis). The number of chronic health conditions was added, and a dichotomous variable ( $\leq 2$ chronic diseases and $\geq 3$ chronic diseases) was created.

Disability levels were measured using the Katz index of independence in activities of daily living scale (Katz et al., 10). The scale measures self-care tasks including bathing, dressing, toileting, transferring to and from a chair, feeding, and maintaining continence. The Turkish version of this scale was assessed by Pehlivanoğlu et al. (11) for its validity and reliability, and the Cronbach alpha coefficient was 0.83 . The Cronbach alpha coefficient was 0.85 in this study.

\section{Cognitive and physical functioning}

The Lawton instrumental activities of daily living scale was developed by Lawton and Brody (12) to assess independence level and physical functioning. It contains eight items which are rated trichotomously (i.e., $1=$ unable, $2=$ able with help, $3=$ able without help). Reliability and validity of the Turkish version was assessed in the present study, and the Cronbach alpha coefficient was 0.95 .

SMMSE was originally developed by Folstein et al. (13). The SMMSE measures different domains of cognitive function such as orientation to time and place, short-term recall, and construct a diagram. The validity and reliability of the Turkish version of the SMMSE was determined by Güngen et al. (14). It had high valid and reliable properties for the diagnosis of mild dementia in the Turkish population.

\section{Social engagement with life}

In line with existing research $(15,16)$, participants were defined as being actively engaged if they reported, first, having provided any grandchild care during the past 12 months or having done "any paid work" or "voluntary or charity work" in the year preceding the interview, and second, if they reported having "spent time with their neighbours" for a social visit or a chat at least once a week or having "providing assistance to family, friends or neighbors or attending a sports, social or other type of club" in the month preceding the interview.

\section{Psychological well-being}

This scale consists of 18 items with 5 rating points ranging from 1 to 5 (17). The obtainable total score varies between 18 and 90 . A high score indicates the higher psychological well-being. This measurement tool was adapted for Turkey by Imamoglu (18), and its Cronbach alpha coefficient was reported to be 0.79 . The Cronbach alpha was 0.94 in this study.

\section{Dependent variable}

Consistent with Rowe and Kahn (5), SA was defined as having a) high physical and cognitive functioning b) no chronic disease [Similar to Wu et al. (19) study, we revised the range of this criterion and classified adults with no more than two chronic diseases as successful adults] and disability c) being actively engaged with life. In order to determine the number of successful agers, in the first step, each criterion were scored as 1 or 0 for meeting or not meeting criteria for each participants (see Table 2). In the second step, we created a dichotomous/ binary variable of having all five (1) or fewer than five (0) indicators. In other words, the participants with high physical and cognitive functioning, and few chronic diseases and no disability and active social engagement were classified as aging successfully. Psychological well-being was taken as an indicator of psychosocial SA.

\section{Statistics}

Prior to the data analyses, recommended assumptions of univariate and multivariate outliers, normality and multicollinearity were checked for each scale. The distribution and normality of the variables were assessed by graphical and statistical methods (20). Mann-Whitney U and Kruskal-Wallis test were used to compare the psychological well-being scores according to the socio-demographic data of the adults. In cases of a significant difference between three or more groups,

\begin{tabular}{|c|c|}
\hline Indicators of successful aging & n (\%) \\
\hline \multicolumn{2}{|l|}{ The number of chronic diseases } \\
\hline$\leq 2$ chronic diseases* & $41(67.2)$ \\
\hline$\geq 3$ chronic diseases ${ }^{* *}$ & $20(32.8)$ \\
\hline \multicolumn{2}{|l|}{ Katz ADL } \\
\hline Independent/no disability ${ }^{*}$ & $47(77.0)$ \\
\hline Moderate or severe functional impairment ${ }^{* *}$ & $14(23.0)$ \\
\hline \multicolumn{2}{|l|}{ Lawton IADL } \\
\hline High physical functioning* & $44(72.1)$ \\
\hline Moderate or low physical functioning** & $17(27.9)$ \\
\hline \multicolumn{2}{|l|}{ SMMSE } \\
\hline Normal cognitive functioning* & $40(65.6)$ \\
\hline Mild cognitive impairment ${ }^{* *}$ & $21(34.4)$ \\
\hline \multicolumn{2}{|l|}{ Social engagement with life } \\
\hline Yes $^{*}$ & $54(88.5)$ \\
\hline $\mathrm{No}^{* *}$ & 7 (11.5) \\
\hline \multicolumn{2}{|l|}{ Successful aging } \\
\hline Yes $^{*}$ & $35(57.4)$ \\
\hline $\mathrm{No}^{* *}$ & $26(42.6)$ \\
\hline \multicolumn{2}{|c|}{$\begin{array}{l}\text { *: Proportion of successful agers, }{ }^{* *} \text { : Proportion of usual agers, SMMSE: Standardized } \\
\text { mini mental state examination test, IADL: Instrumental activities of daily living, ADL: } \\
\text { Activities of daily living }\end{array}$} \\
\hline
\end{tabular}


using a Bonferonni corrected p-value, follow-up post-hoc tests applied. The relationship between categorical data was assessed using the chi-square test. In order to assess correlations among subjective health, subjective age and dimensions of SA, Spearman rho statistic was computed. All data was analysed using $R(21)$. A p-value less than $0.05(p<0.05)$ was taken to indicate statistical significance.

\section{Results}

$67.2 \%$ of the participants had fewer than three chronic diseases, and $77.0 \%$ of those with no disability (Table 2). Slightly twothirds of participants met the physical and cognitive functioning criterion $(72.1 \%$ and $65.6 \%$, respectively). The majority of the participants (88.5\%) met the social engagement criteria and were socially active. According to these five criteria, 35 (57.4\%) participants were successful in aging.

Table 1 and Table 3 summarise the results of all relationships between the independent variables and dependent variables. As seen in Table 1, the community-dwelling adults were more likely to experience SA than the adults who were living in nursing homes ( 86.7 vs. $29.0 \%) \chi^{2}(1)=20.71, p<0.001$. Adults ages 50 to 64 were more likely to experience SA than the adults who were
65 or older (71.4 vs. $45.5 \%) \chi^{2}(1)=4.18, p=0.041$. Furthermore, the married adults were more likely to experience $\mathrm{SA}$ than the single adults ( 92.9 vs. $46.8 \%) \chi^{2}(1)=9.35, p=0.002$. A difference was also observed in the educational levels $\chi^{2}(4)=18.26$, $\mathrm{p}=0.001$. Post hoc tests using a Bonferroni correction indicated that adults having college (91.7\%) and associate degrees or more educated adults (80.0\%) were more likely to experience SA than the adults having only literature (45.5\%), primary (25.0\%) and secondary (36.4\%) educations. However, in this study, we did not find any differences based on gender or the number of children an individual had ( $p>0.05$ ).

As seen in Table 3, the Mann-Whitney $U$ test showed that psychological well-being scores of adults ages 50-64 $(M d n .=58.0)$ were higher than the scores of adults ages 65 or older (Mdn. $=42.0) \mathrm{U}=297.00, p=0.017$. In addition, psychological well-being scores of married adults $(\mathrm{Mdn} .=69.5)$ were higher than those of single adults ( $M d n .=44.0) U=182.50, p=0.012$. A Kruskal-Wallis test indicated that the adult's educational groups differed significantly in terms of $S A \chi^{2}(4)=13.40, p=0.009$. Posthoc Mann-Whitney $\mathrm{U}$ tests indicated that the psychological well-being scores of adults who had associate degrees or higher $(M d n .=68.0)$ was significantly better than that of literature

\begin{tabular}{|c|c|c|c|c|c|c|}
\hline Associated factors & Mean rank & Median & Min. & Max. & $x^{2} / U$ & p \\
\hline Living space* & - & - & - & - & 384.50 & 0.245 \\
\hline Nursing home residents & 28.4 & 50.0 & 26.0 & 73.0 & - & - \\
\hline Community-dwelling adults & 33.7 & 60.0 & 27.0 & 80.0 & - & - \\
\hline Age $^{*}$ & - & - & - & - & 297.00 & 0.017 \\
\hline $50-64$ & 36.9 & 58.0 & 27.0 & 80.0 & - & - \\
\hline 65 or more & 26.0 & 42.0 & 26.0 & 76.0 & - & - \\
\hline Gender* & - & - & - & - & 399.50 & 0.418 \\
\hline Female & 28.9 & 43.0 & 26.0 & 80.0 & - & - \\
\hline Male & 32.6 & 54.0 & 27.0 & 77.0 & - & - \\
\hline Marital status* & - & - & - & - & 182.50 & 0.012 \\
\hline Single & 27.9 & 44.0 & 26.0 & 76.0 & - & - \\
\hline Married & 41.5 & 69.5 & 29.0 & 80.0 & - & - \\
\hline Number of children ${ }^{* * *}$ & - & - & - & - & 4.24 & 0.236 \\
\hline 0 & 19.0 & 32.0 & 26.0 & 69.0 & - & - \\
\hline 1 & 33.2 & 64.0 & 29.0 & 76.0 & - & - \\
\hline 2 & 34.1 & 50.0 & 30.0 & 80.0 & - & - \\
\hline 3 or more & 29.5 & 48.0 & 27.0 & 73.0 & - & - \\
\hline Education $^{* * *}$ & - & - & - & - & 13.40 & 0.009 \\
\hline Literature & 20.5 & 38.0 & 26.0 & 65.0 & - & - \\
\hline Primary school & 25.3 & 43.5 & 30.0 & 72.0 & - & - \\
\hline Secondary school & 28.2 & 48.0 & 30.0 & 71.0 & - & - \\
\hline College & 32.8 & 53.5 & 27.0 & 80.0 & - & - \\
\hline Associate degree or more & 43.9 & 68.0 & 34.0 & 76.0 & - & - \\
\hline
\end{tabular}


$(M d n .=38.0) p<0.001$ and primary school graduates $(M d n .=43.5)$ $\mathrm{p}=0.003$.

Lastly, psychological well-being is positively correlated with the biomedical dimension of $S A(r=0.54, p<0.001)$, subjective age $(r=0.31, p=0.017)$ and subjective health $(r=0.59 p<0.001)$. Moreover, the biomedical dimension of SA is positively related to subjective age $(r=0.26 p=0.045)$ and subjective health $(r=0.66$ $\mathrm{p}<0.001$ ) (Table 4).

\section{Discussion}

This research represents an early step in the determination of related factors with two main approaches to SA. One of the most interesting findings is that living space is srelated to Rowe et al. (5) SA model, but not to psychological well-being. This finding can be explained by the fact that the health status of adults living in nursing homes is worse than that of the community-dwelling adults. However, well-being is a more subjective and personcentered concept as compared to health status; therefore, we may not have found a significant difference between the two groups for well-being. Consistent with our study, Scheidt et al. (22) indicated that Rowe and Kahn's definition is very narrow, and there may be adults who do not meet these criteria but who are successful agers. This finding is especially noteworthy and should be addressed in future research. Those adults who were inconsistent in terms of the two conceptual definitions may hold the key to understanding what SA is really all about.

Some researchers found that men were more successful than women meet the criteria of Rowe et al.s SA (1). However, other studies have suggest that more women than men have a higher prevalence of SA (23). The results of our study showed no significant gender differences in SA. This result is consistent with those of McLaughlin et al. (4) specifying that no significant gender difference was observed in SA among United States adults.

In line with previous studies (24), we speculated that adults with more children may have more physical and social support from their children, as compared to those who have fewer children, and therefore, we expected that the number of children would positively affect SA. However, we did not find SA benefits with regard to a greater number of children. We also conducted additional analysis and found no significant difference in SA rates among adults with and without children. The reason why these variables are not related to SA may be the relatively small sample size.

Ferri et al. (9) suggest that better health is associated with higher ratings on SA. Similarly, Whitley et al. (25) explored associations between Rowe-Kahn SA components and subjective health and concluded that all individual positive SA components were associated with better subjective health. In line with these studies, we found that as the evaluations of subjective health moved from very good to very bad, the level and proportion of those aging successfully decreased. This finding is important and noteworthy. How an individual feels about herself/himself in terms of health status may be the predictor of SA, and there may be a causal relationship between the two. Therefore, future research should evaluate these relationships longitudinally.

In light of the Palgi et al. (26) study, we expected there to be a relationship between subjective age and $S A$, and we found that younger subjective age is related to better SA. This result might be based on several factors. First of all, individuals who feel younger may be involved in more physical and social activities, and this may make them feel like successful agers. Another factor may be that a younger subjective age provides a positive psychological environment by increasing self-esteem and coping skills in the face of increasing problems with age, which may, in turn, promote SA.

An earlier study regarding the marital status and SA that was conducted in 2006 found that being currently married contributed to successful aging (27). A recent study conducted in 2018 reported that married participants are more likely to be successful agers (28). In accordance with those studies, our data revealed that the rate of successful aging was higher in married individuals. This result might be based on several factors. First of all, many researchers show that being

\begin{tabular}{|c|c|c|c|c|c|c|c|}
\hline & Mean \pm SD & Median (Min-max) & & 1 & 2 & 3 & 4 \\
\hline \multirow{2}{*}{ 1. Psychological well-being } & $51.3 \pm 16.9$ & $50.0(26.0-80.0)$ & $r$ & - & - & - & - \\
\hline & - & - & $\mathbf{p}$ & - & & - & - \\
\hline \multirow{2}{*}{ 2. Biomedical model of successful aging* } & - & - & $r$ & 0.536 & - & - & - \\
\hline & - & - & $\mathbf{p}$ & 0.000 & - & - & - \\
\hline \multirow{2}{*}{ 3. Subjective age } & $6.3 \pm 8.0$ & $4.0(-9.0-25.0)$ & $r$ & 0.305 & 0.258 & - & - \\
\hline & - & - & $\mathbf{P}$ & 0.017 & 0.045 & - & - \\
\hline \multirow{2}{*}{ 4. Subjective health } & $3.2 \pm 1.2$ & $3.0(1.0-5.0)$ & $r$ & 0.588 & 0.664 & 0.413 & - \\
\hline & - & - & $\mathbf{p}$ & 0.000 & 0.000 & 0.001 & - \\
\hline
\end{tabular}


married is associated with many health benefits $(29,30)$. Another possible explanation for this result is that married adults might be more likely to engage social activities (e.g., visiting relatives) and may also be less exposed to stressful life situations than single adults due to their greater financial power which may, in turn, promote SA. However, it should be note that some researchers indicated that high marital quality was associated lower stress, less depression, and higher satisfaction with life, therefore, marriage must be of a high quality to be advantageous. In other words, one is better off single than unhappily married (31).

Consistent with previous studies $(1,23,32,33)$, this study shows that SA was related to age, educational level and marital status. More specifically, there was a higher rate of successful aging among those in the younger age category, those with higher education levels, and those who were married. As a matter of fact, these findings are well known from previous studies, and a consensus has been reached in many studies, as noted above.

\section{Study Limitations}

This study has some limitations. The first limitation of the present study was the relatively small number of participants, and future research for a similar purpose should include larger samples. Second, the study had a cross-sectional design which provides no information on causal relationships; therefore, longitudinal studies are required to more clearly establish the causal relationship between socio-demographic factors and SA. Moreover, the depression status of the patients may have affected answers to all subjective questions, but we did not investigate this variable. For this reason, the depression status should be included in future research as a covariate or control variable. On the other hand, our study's strengths include its comprehensive, two main approaches to SA based on a large set of objective and subjective functioning measures.

\section{Conclusion}

Overall, our study demonstrated that the biomedical and psychosocial dimensions of SA are related to the similar socio-demographic factors along with subjective health and age. These findings suggest that subjective age and health status, which are changeable and relatively under the control of the individuals, are important to promote SA. However, it is important to avoid blaming adults for their unsuccessful aging status, as having these socio-demographic factors is not under the control of most adults. However, social, cultural and psychological opportunities that increase individuals' ability to feel they are younger and better health should not be abandoned, multipronged approaches are needed to enhance SA. These methods should include policies to reduce socioeconomic inequalities and related health disparities.

\section{Ethics}

Ethics Committee Approval: The study was approved by the Ethics Board and Commission of Ege University in Turkey (approval number: 204-2019).

Informed Consent: Written informed consent was obtained from participants.

Peer-review: Externally peer-reviewed.

\section{Authorship Contributions}

Concept: C.S., T.Y.I., Design: C.S., T.Y.I., Data Collection or Processing: C.S., Analysis or Interpretation: C.S., T.Y.I., Literature Search: C.S., Writing: C.S.

Conflict of Interest: No conflict of interest was declared by the authors.

Financial Disclosure: This study was produced from a part of the first author's work on his doctoral thesis, which was supported by the "Koç University Prof. Dr. Çiğdem Kağıtçıbaşı Human Development Research Award" in 2020.

\section{References}

1. Hamid TA, Momtaz YA, Ibrahim R. Predictors and prevalence of successful aging among older Malaysians. Gerontology 2012;58:366-370.

2. United Nations. World Population Ageing 2019.Available from: https:// www.un.org/en/development/desa/population/publications/pdf/ageing/ WorldPopulationAgeing2019-Report.pdf

3. Bowling A, Dieppe P. What is successful ageing and who should define it? BMJ 2005;331:1548-1551.

4. McLaughlin SJ, Connell CM, Heeringa SG, Li LW, Roberts JS. Successful aging in the United States: prevalence estimates from a national sample of older adults. J Gerontol B Psychol Sci Soc Sci 2010;65B:216-226.

5. Rowe JW, Kahn RL. Successful aging. Gerontologist 1997;37:433-440

6. Cosco TD, Prina AM, Perales J, Stephan BC, Brayne C. Operational definitions of successful aging: a systematic review. Int Psychogeriatr 2014;26:373381.

7. Stephan Y, Demulier V, Terracciano A. Personality, self-rated health, and subjective age in a life-span sample: the moderating role of chronological age. Psychol Aging 2012;27:875-880

8. John D, Lang FR. Subjective acceleration of time experience in everyday life across adulthood. Dev Psychol 2015;51:1824-1839.

9. Ferri C, James I, Pruchno R. Successful aging: Definitions and subjective assessment according to older adults. Clin Gerontol 2009;32:379-388.

10. Katz S, Ford AB, Moskowitz RW, Jackson BA, Jaffe MW. Studies of Illness in the Aged. The index of Adl: A standardized measure of biological and psychosocial function. JAMA 1963;185:914-919.

11. Pehlivanoğlu EFÖ, Özkan MU, Balcıoğlu H, Bilge U, Ünlüoğlu i. Adjustment and reliability of katz daily life activity measures for elderly in Turkish. Ank Med J 2018;18:219-223.

12. Lawton MP, Brody EM. Assessment of older people: self-maintaining and instrumental activities of daily living. Gerontologist 1969;9:179-186.

13. Folstein MF, Folstein SE, McHugh PR. "Mini-mental state". A practical method for grading the cognitive state of patients for the clinician. J Psychiatr Res 1975;12:189-198.

14. Güngen $C$, Ertan T, Eker E, Yaşar R, Engin F. Standardize Mini Mental test'in türk toplumunda hafif demans tanisinda geçerlik ve güvenilirliği [Reliability 
and validity of the standardized Mini Mental State Examination in the diagnosis of mild dementia in Turkish population]. Turk Psikiyatri Derg 2002;13:273-281.

15. Brandt M, Deindl C, Hank K. Tracing the origins of successful aging: the role of childhood conditions and social inequality in explaining later life health. Soc Sci Med 2012;74:1418-1425.

16. Hank K. How "successful" do older Europeans age? Findings from SHARE. J Gerontol B Psychol Sci Soc Sci 2011;66:230-236.

17. Ryff CD, Keyes CL. The structure of psychological well-being revisited. J Pers Soc Psychol 1995;69:719-727.

18. Imamoğlu EO. Self-construal correlates of well-being. 2004; (Unpublished data).

19. Wu M, Yang $Y$, Zhang D, Sun $Y$, Xie H, Zhang J, Jia J, Su Y. Prevalence and related factors of successful aging among Chinese rural elders living in nursing homes. Eur J Ageing 2017;14:419-428.

20. Tabachnick BG, Fidell LS. Using multivariate statistics, 6th ed. New Jersey: Pearson Education; 2013.

21. R Core Team. R: A language and environment for statistical computing. Austria: 2016.

22. Scheidt RJ, Humpherys DR, Yorgason JB. Successful aging: What's not to like? J Appl Gerontol 1999;18:277-282.

23. Bosnes I, Almkvist O, Bosnes O, Stordal E, Romild U, Nordahl HM. Prevalence and correlates of successful aging in a population-based sample of older adults: the HUNT study. Int Psychogeriatr 2017;29:431-440.

24. Freedman VA, Kasper JD, Spillman BC. Successful Aging Through Successful Accommodation With Assistive Devices. J Gerontol B Psychol Sci Soc Sci 2017;72:300-309.
25. Whitley E, Popham F, Benzeval M. Comparison of the Rowe-Kahn Model of Successful Aging With Self-rated Health and Life Satisfaction: The West of Scotland Twenty-07 Prospective Cohort Study. Gerontologist 2016;56:10821092.

26. Palgi Y, Shrira A, Avidor S, Hoffman Y, Bodner E, Ben-Ezra M. Understanding the long-term connections between posttraumatic stress, subjective age, and successful aging among midlife and older adults. Eur J Psychotraumatol 2019;10:1583523.

27. Li C, Wu W, Jin H, Zhang $X$, Xue H, He Y, Xiao S, Jeste DV, Zhang M. Successful aging in Shanghai, China: definition, distribution and related factors. Int Psychogeriatr 2006;18:551-563.

28. Canêdo AC, Lopes CS, Lourenço RA. Prevalence of and factors associated with successful aging in Brazilian older adults: Frailty in Brazilian older people Study (FIBRA RJ). Geriatr Gerontol Int 2018;18:1280-1285.

29. Sommerlad A, Ruegger J, Singh-Manoux A, Lewis G, Livingston G. Marriage and risk of dementia: systematic review and meta-analysis of observational studies. J Neurol Neurosurg Psychiatry 2018;89:231-238.

30. Bulanda JR, Brown JS, Yamashita T. Marital quality, marital dissolution, and mortality risk during the later life course. Soc Sci Med 2016;165:119-127.

31. Holt-Lunstad J, Birmingham W, Jones BO. Is there something unique about marriage? The relative impact of marital status, relationship quality, and network social support on ambulatory blood pressure and mental health. Ann Behav Med 2008;35:239-244.

32. Cooney TM, Curl AL. Transitioning From Successful Aging: A Life Course Approach. J Aging Health 2019;31:528-551.

33. Yalcinoz Baysal $H, A k \operatorname{tas} B, B a k a n A B$. An investigation of the relationship between ageing in place and successful ageing in elderly individuals. Psychogeriatrics 2020;20:473-479. 